\title{
A Cross-Sectional Study on Practices of Veterinarians Towards the Use of Ceftriaxone in Dogs in Enugu State, Nigeria
}

\author{
Eze $\mathrm{UU}^{* 1}$, Eke $\mathrm{IG}^{2}$, Anaga $\mathrm{AO}^{2}$, Udeani $\mathrm{IJ}^{3}$, Ezenduka $\mathrm{EV}^{4}$ and Anene $\mathrm{BM}^{1}$ \\ ${ }^{1}$ Department of Veterinary Medicine, Faculty of Veterinary Medicine, University of Nigeria \\ ${ }^{2}$ Department of Veterinary Physiology and Pharmacology, Faculty of Veterinary Medicine, University of Nigeria \\ ${ }^{3}$ University of Nigeria Veterinary Teaching Hospital, University of Nigeria, Nsukka \\ ${ }^{4}$ Department of Veterinary public Health and Preventive Medicine, Faculty of Veterinary Medicine, University of Nigeria \\ *Corresponding author: ukamakauchenna.eze@unn.edu.ng
}

\begin{abstract}
Article History: $20-128$
Received: 30-May-20

Revised: 11-Nov-20

Accepted: $18-$ Nov-20

\section{ABSTRACT}

The indiscriminate use of ceftriaxone in animals could be the source of increase in ceftriaxone-resistant bacterial infections in human. The aim of this study was to evaluate the knowledge, attitude, and practices of veterinarians towards the use of ceftriaxone in dogs in Enugu State Nigeria. A cross sectional survey was conducted using validated structured questionnaire. Eighty (98\%) out of 82 veterinarians who participated in this study returned their completed questionnaire. Recurrence of bacterial infection after treatment significantly $\left[\chi^{2}(2)=24.36(\mathrm{P}<0.01)\right]$ increased with lower brand price of ceftriaxone used by veterinarians. The occurrence of side effect also showed a strong correlation $(r=0.9597 ; \mathrm{P}<0.01)$ with increased dose of ceftriaxone administered. Out of the 26 and 57 respondents who admitted to have had the knowledge that ceftriaxone is an extra- label drug used in dogs and one of the drugs of last resort, 11.5 and $19.3 \%$ applied culture and sensitivity tests before its use, respectively. This study has shown that there is a public health threat as lavish use of ceftriaxone in dogs may be responsible for the increase in ceftriaxone- resistant bacterial infections seen as recurrence of infection after treatment.
\end{abstract}

Key words: Ceftriaxone, Veterinarians, Dogs, Cross-sectional Survey.

@2020 IJVS - All Rights Reserved

\section{INTRODUCTION}

Ceftriaxone, a third-generation cephalosporin is one of the most important antimicrobials used in human medicine especially in critically ill patients (Joynt et al. 2001). It is one of the drugs of last resort because of its strong activity against penicillinase producing enterobacteriaceae (WHO 2016; Colakoglu et al. 2017). As an important antibiotic for humans, ceftriaxone is not meant to be used in non-humans, thus, there is no animal preparations of the drug. However, ceftriaxone is permitted to be used as an extra-label drug in non-food producing animals such as dogs (FDA 2018). The drug has been used as an extra-label drug in the treatment of different animal bacterial diseases such as mastitis in cows, staphylococcal endocarditis and lower urinary tract infection in dogs among other diseases at different doses (Gavaldà et al. 2002; Tapas 2013; Colakoglu et al. 2017).

The past few decades have witnessed a significant increase in antibiotic use globally (Boeckel et al. 2014), with an increase in antimicrobial resistance (AMR). AMR can be described as the ability of microbes, such as bacteria, fungi, protozoan, viruses etc, to become resistant to an antimicrobial to which they were previously susceptible to, thereby causing the infection to persist in the body and possibly spread to others (WHO 2015; European Commission 2017; Mehmood et al. 2020). This resistance to antimicrobials can be acquired either by mutations of already existing genes or acquisition of new gene from other bacteria known as horizontal gene transfer (HGT) (Boerlin and Reid-Smith 2008). In developing countries such as Nigeria, AMR is escalating and its incidence in humans has been linked to the indiscriminate use of antibiotics in animals (Bengtsson and Grek 2014; Gashe et al. 2018; Mohsin et al. 2019). Initially, the susceptibility of both gram negative and gram-positive bacteria to ceftriaxone made it a drug of choice in treatment of several infections. The issue of antimicrobial resistance is a major public health concern as it increases the risk of inappropriate therapy thus

Cite This Article as: Eze UU,Eke IG,Anaga AO, Udeani IJ, Ezenduka EV and Anene BM, 2020. A cross-sectional study on practices of veterinarians towards the use of ceftriaxone in dogs in Enugu state, Nigeria. International Journal of Veterinary Science 10(3): 220-228. https://doi.org/10.47278/journal.ijvs/2021.039 
leading to increased morbidity and mortality (Kapil 2005; Ventola 2015). One of the major challenges facing veterinary medical care is multi-drug resistant infections which is a huge burden. This is not only because it affects the cost and effect of treatment, but these multi-drug resistant organisms can be transferred to humans thereby posing a great public health risk.

Dogs are companion animals and live-in close proximity to human; therefore, zoonotic diseases are easily transferable between them. In the same manner, pet dogs harboring drug resistant bacteria can contaminate the household environment with the resistant bacteria and or resistant genes, thus directly leading to human infection with AMR bacteria (Loeffler et al. 2005; Marshall and Levy 2011; Pomba et al.2017). This is made possible especially since resistant genes are transmissible across species through many routes such as formites, food, water, grooming brushes, litter pans etc (Van Boeckel et al. 2015; McEachran et al. 2015; Chung et al. 2017). Studies have shown that lavish use of antibiotics in pet dogs among other things such as over-the-counter sales of antibiotics, poor sanitation and hygiene, consumption of antibiotic residues in meat, etc. may contribute to genetic selection pressure of these microbes and consequent emergence of multi drug resistant bacteria (Aslam et al. 2018). In a study carried out in dogs with deep pyoderma, it was observed that owners of such dogs carry multiple antimicrobial-resistant strains of Staphylococcus intermedius. This finding was attributed to the transfer of resistance genes from dog Staphylococcus intermedius to human pathogenic staphylococci probably through close contact (Guardabass et al. 2004). In a survey study conducted on field Veterinarians in India, it was observed that $21 \%$ believed that the main mode of transmission of resistant bacteria from animal to humans was through direct contact between humans and animals, 20\% thought of consumption of animal products as the major route, $5 \%$ considered mobile genetic materials while $2 \%$ factored contaminated environment (Parkunan et al. 2019).

The primary duty of a veterinarian is to ensure the overall wellbeing of animals, which involves essentially making a diagnosis and treating the infected or diseased animal whilst preventing other animals from getting infected. In the United States, if the infection is of bacterial origin, the veterinarian is expected to implement antimicrobial stewardship (AMS) programs; which involves effective infection control, bacteriologic culture, antimicrobial susceptibility testing, and the use of individual practice guidelines for AMS which could be done only within the valid veterinarian-client-patient relationship to ensure appropriate use (Prescott and Boerlin 2016; FDA 2017; AVMA 2018).

In Nigeria, laws guiding the use of antibiotic in animals are not strictly enforced, hence the improper and indiscriminate use of antibiotics in food animals which fuels the increase in drug resistant bacteria in the country (Oloso et al. 2018). Since reports have shown that ceftriaxone-resistant bacteria are recently on the increase (Gashe et al. 2018; Muhie 2019) and it being a drug often used in critically ill human patients, this study was therefore designed to ascertain the knowledge, attitude, and practices of veterinarians towards the use of ceftriaxone in Enugu State, Nigeria.

\section{MATERIALS AND METHODS}

Ethical Approval: The study was approved by the Research Ethics Committee of the Faculty of Veterinary Medicine, University of Nigeria (UNN/FVM/MDf/ 14035). Veterinarians who participated were clearly informed about the study and guaranteed about the confidentiality of their answers. All the respondents participated voluntarily.

\section{Study Area}

The study was conducted in Enugu State in Southeastern part of Nigeria which is located between latitude $6^{\circ} 45^{1}$ and $7^{\circ} \mathrm{N}$ and longitude $7^{\circ} 12.5^{1}$ and $7^{\circ} 36^{1} \mathrm{~W}$ in the Southeast geopolitical zone of Nigeria. It covers a total land area of $7617.82 \mathrm{sqkm}$. It has three Senatorial zones and 17 local government areas. There are more than 150 registered veterinarians in the State who practice in teaching hospital, State general hospital, local government clinics or private establishments.

\section{Study Design}

The study was a cross-sectional survey using a structured close-ended questionnaire with both dichotomous and multichoice questions. The questionnaire was validated in the Department of Veterinary Public Health and Preventive Medicine, University of Nigeria, Nsukka. Only the veterinarians who offer clinical services to government hospitals or private clinics were included in the study. A total of 82 copies of questionnaire were distributed to veterinarians who render services at University of Nigeria Veterinary Teaching Hospital, Enugu State Veterinary Clinic, Uwani, Enugu, and private veterinary clinics in Enugu metropolis. The questionnaire was divided into 4 parts, the first part covered the respondent bio-data, the second aspect was on veterinary practice and part three was on the use of ceftriaxone in dogs while part four was on the knowledge of the status of ceftriaxone use in dogs.

\section{Statistical Analysis}

Results were summarized using descriptive statistics on the GraphPad prism statistical package version 5.2 for Windows (GraphPad Software, La Jolla California USA, http://www.graph pad.com). Chi square test was used to test association between dependent and independen variables with categorical data as stated in Table 1. Odds ratio was used to determine the strength of association between the variables. Correlation analysis was done to test relationship between variables with discrete data. Significance level was accepted at $\mathrm{P}<0.05$.

\section{RESULTS}

\section{Bio-data and Practice Characteristics of Respondents} There was a total of $80(98 \%)$ veterinarians who completed and returned their questionnaires out of the 82 copies distributed. The distribution of sex, age, and educational qualifications of respondents are presented in Table 2A. There were more males than female respondents in the study area. The respondents were mostly young veterinarians who were between the ages of $31-40$ years $(58.3 \%)$. A good number $(41.7 \%)$ of the 
respondents have completed their Masters degree, while only $2(2.1 \%)$ have both $\mathrm{PhD}$ and Membership qualification, but none was a Fellow of College of Veterinary Surgeons of Nigeria. Most $(83.3 \%)$ of the respondents were private clinicians. A total of $50(62.5 \%)$ of the respondents reported using ceftriaxone to treat dogs. All $(100 \%)$ the respondents agreed to be aware of antibiotic resistance, while only a few $13.8 \%$ admitted to have applied sensitivity test result before commencement of treatment with ceftriaxone as shown in Table $2 \mathrm{~B}$.

\section{Purpose of Prescribing Ceftriaxone for Dogs}

Of the 50 respondents who admitted use of ceftriaxone antibiotic, 22, 48 and $30 \%$ used it to treat mild, severe and very severe bacterial infection of dogs, respectively. Thirty-three $(66 \%)$ of the respondents used ceftriaxone in the prevention of secondary bacterial infection, while $17(34 \%)$ of the respondents used it to treat secondary bacterial complication following a viral infection as shown in Table 3.

Association Between the Duration of Veterinary Practice and Inclination to Use Ceftriaxone for Treatment of Bacterial Infection

The result of this study showed that there was a significant association $\chi^{2}(2)=14.18(\mathrm{P}<0.01)$ between the duration of practice of respondents and inclination to use ceftriaxone in the treatment of bacterial infection as shown in Fig. 1. It appears that those who have practiced for 1 to 20 years used ceftriaxone more often than those who had practiced longer than 20 years.

\section{Association Between the Type of Veterinary Clinical Practice and the Use of Ceftriaxone}

There was a significant association $\chi^{2}(2)=33.25$ $(\mathrm{P}<0.01)$ between species of animals being treated by the respondents and the use of ceftriaxone as the drug of choice, showing that veterinarians in Enugu State used ceftriaxone more in small animal and mixed clinical practices than in avian clinical practice as shown in Fig. 2.

Age of the Respondents and Inclination to Use of Ceftriaxone for Treatment

There was a significant association $\chi^{2}(3)=33.20$ $(\mathrm{P}<0.01)$ between the age of the respondents and the inclination to use ceftriaxone for treatment of bacterial infection as shown in Fig. 3. The younger the respondents, the more they are inclined to choose ceftriaxone in the treatment of infection.

\section{Association Between the Brand Prices of Ceftriaxone and Recurrence of Infection}

There was a significant association between the different brand prices of ceftriaxone and recurrence of infection after treatment $\chi^{2}(2)=24.36(\mathrm{P}<0.01)$. The lower the price of ceftriaxone used by the respondents in treatment of infection in dogs, the more likely the infection will recur after treatment and vice versa (Fig. 4).

Relationship Between Doses of Ceftriaxone Used by the Respondents in Treatment of Infection in Dogs and Risk of Side Effect Manifestation

All the respondents gave varied doses of ceftriaxone to animals since there was no known stipulated dose for any animal species. A total of 30 (37.5\%) of the respondents who administered ceftriaxone at the dose of $40-50 \mathrm{mg} / \mathrm{kg}$ reported that they did so because it is the human dosage. Out of 18, 80 and $100 \%$ respondents who administered 40 and $50 \mathrm{mg} / \mathrm{kg}$ of ceftriaxone, respectively, reported seeing dogs manifest side effects when treated with these doses. Side effects reported include; inappetence, pale mucous membrane, mucopurulent eye discharge, diarrhea, bilateral paralysis of the hind limb, brown-colored urine and loss of hair. A significant correlation between dose of ceftriaxone administered and manifestation of side effect was found $(r=0.9597 ; \mathrm{P}<0.01)$ (a strong positive linear relationship), in particular higher doses tend to produce side effects as shown in Fig. 5.

\section{Association Between Duration of Treatment and Development of Side Effect}

The study showed that none of the respondent administered ceftriaxone just for one or two days. The duration of treatment in this study was from 3 days up to 2 weeks. There was a significant correlation between the duration of treatment with ceftriaxone and manifestation of side effect ( $r=0.9857, \mathrm{P}<0.01$ ) (a strong positive linear relationship), the longer the duration of treatment, the higher the risk of production of side effects as shown in Fig. 6.

\section{Association Between Duration of Treatment and Recurrence of Infection \\ There was a correlation $(\mathrm{r}=-0.7401 ; \mathrm{P}>0.01)$ (a strong negative linear relationship) between the duration of treatment with ceftriaxone and recurrence of infection as shown in Fig. 7. In other words, recurrence occurred with decrease in duration of treatment with the drug.}

\section{Awareness of Extra-Label Status of Ceftriaxone Use in Dogs and Application of Culture and Sensitivity Result Before Treatment \\ Out of the 80 veterinarians who responded to the questionnaire, $32.3 \%$ indicated that they were aware of the extra-label status of ceftriaxone; among which $11.5 \%$ conduct culture and sensitivity test before its use (Table 4). Fifty-seven $(71.2 \%)$ of the respondents agreed that they were aware that ceftriaxone is one of the drugs of last resort used in humans; among which $19.3 \%$ admitted running a sensitivity test before its use (Table 4).}

Table 1: Analysis of Dependent and Independent variables

\begin{tabular}{cllll}
\hline Sr. No & Dependent Variable & Independent Variables & Analytical tool \\
\hline 1 & Use of Ceftriaxone & $\bullet$ & Duration of practice & Chi-square \\
& & $\bullet$ & Type of clinical practice & Chi-square \\
Chi-square & Age of respondents & Chi-square \\
2. & Recurrence of infection & $\bullet$ & Brand/price of cefriaxone & Correlation \\
& & $\bullet$ & Duration of treatment & Correlation \\
& & $\bullet$ & Doses of ceftriaxone & Duration of treatment
\end{tabular}


Int J Vet Sci, 2021, 10(3): 220-228.

Table 2A: Bio-data and general information of 80 veterinarians who responded to the questionnaire survey in Enugu State Nigeria

\begin{tabular}{ll}
\hline Variables & $\begin{array}{l}\text { Frequency } \\
\mathrm{n}(\%)\end{array}$ \\
\hline Sex & \\
Male & $57(71.2)$ \\
Female & $23(28.8)$ \\
Age & \\
$20-30$ & $20(25)$ \\
$31-40$ & $47(58.8)$ \\
$41-50$ & $10(12.5)$ \\
$51-60$ & $3(3.8)$ \\
61 and above & $0(0)$ \\
Educational qualification & \\
DVM only & $43(54.2)$ \\
M.Sc & $33(41.6)$ \\
MCVSN & $2(2.1)$ \\
PhD & $2(2.1)$ \\
FCVSN & $0(0)$ \\
Place of work & \\
University of Nigeria Teaching Hospital & $10(12.5)$ \\
State Veterinary Clinic & $3(4.2)$ \\
Private Clinics & $67(83.3)$ \\
Duration of clinical practice & \\
Less than a year & $12(15)$ \\
1-10 years & $51(63.8)$ \\
11-20 years & $7(8.7)$ \\
21-30 years & $8(10)$ \\
More than 30 years & $2(2.5)$ \\
Type of clinical practice & \\
Small animal clinical practice & $17(20.8)$ \\
Mixed veterinary clinical practice & $50(62.5)$ \\
Avian clinical practice & $13(16.7)$ \\
Other animals treated with ceftriaxone & \\
Poultry & $8(10.0)$ \\
Pigs & $6(7.5)$ \\
Sheep & $3(3.8)$ \\
Goat & $5(6.3)$ \\
\hline &
\end{tabular}

Cattle

Dose of ceftriaxone prescribed for dogs

$5 \mathrm{mg} / \mathrm{kg}$

$10 \mathrm{mg} / \mathrm{kg}$

$20 \mathrm{mg} / \mathrm{kg}$

$30 \mathrm{mg} / \mathrm{kg}$

$40 \mathrm{mg} / \mathrm{kg}$

$50 \mathrm{mg} / \mathrm{kg}$

Duration of treatment

Stat

2 days

3 days

4 days

5 days

6 days

One week

2 weeks

Treatment regiment

Once daily

Twice daily

Thrice daily

$0(0)$

$10(12.5)$

$25(31.5)$

$10(12.5)$

$5(6.3)$

$15(18.7)$

$15(18.7)$

$0(0)$

$0(0)$

$27(34.5)$

$6(6.9)$

$37(48.3)$

$6(6.9)$

$3(3.4)$

$1(1.3)$

$68(84.4)$

$12(15.6)$

$0(0)$

Other antibiotics most commonly used in clinical practice

Tetracycline $\quad 37(46.3)$

Gentamycin $11(13.8)$

Neomycin $\quad 0(0)$

Tylosin $1(1.3)$

Penicillin $\quad 0(0)$

Streptomycin $0(0)$

Penicillin and streptomycin combination $\quad 18(22.5)$

Amoxicillin $6(7.5)$

Ciprofloxacin $4(5)$

Colistin 3 (3.8)

Reason for not applying antibiotic sensitivity test

before commencement of treatment with ceftriaxone

Very burdensome 8 (11.6)

Unavailability of standard microbiology laboratory $42(60.9)$

Pressure from the clients 19 (27.5)

Very expensive 0

Table 2B: Dichotomous questions

\begin{tabular}{lccccc}
\hline Response & $\begin{array}{c}\text { Use of ceftriaxone } \\
\text { in dogs }\end{array}$ & $\begin{array}{c}\text { Knowledge of } \\
\text { Antibiotic Stewardship }\end{array}$ & $\begin{array}{c}\text { Application of antibiotic } \\
\text { stewardship protocol }\end{array}$ & $\begin{array}{c}\text { Awareness of } \\
\text { antibiotics resistance }\end{array}$ & $\begin{array}{c}\text { Application of culture } \\
\text { and sensitivity }\end{array}$ \\
\hline YES $n(\%)$ & $50(62.5)$ & $1(1.3)$ & $0(0)$ & $80(100)$ & $11(13.8)$ \\
NO $n(\%)$ & $30(37.5)$ & $79(98.7)$ & $80(100)$ & $0(0)$ & $69(86.2)$ \\
\hline
\end{tabular}

n: numbers, DVM: doctor of veterinary medicine, M.Sc: Master of science, MCVSN: member college of veterinary medicine Nigeria, $\mathrm{PhD}$ : doctor of philosophy, FCVSN: fellow college of veterinary surgeons Nigeria.

Table 3: Purpose and clinical use of ceftriaxone in dogs by fifty (50) respondents

\begin{tabular}{lc}
\hline Purpose of use of ceftriaxone & $\mathrm{n}(\%)$ \\
\hline Severity of infection & $11(22)$ \\
Mild infection & $24(48)$ \\
Severe infection & $15(30)$ \\
$\quad$ Very severe infection & $33(66)$ \\
Management of secondary bacterial infection following viral infection & $17(34)$ \\
$\quad$ Prevention of secondary bacterial infection & \\
Treatment of secondary bacterial complication & \\
\hline
\end{tabular}

Table 4: Awareness of the status of ceftriaxone and the application of culture and sensitivity before treatment

\begin{tabular}{clccc}
\hline S/N & Variables & Positive responses (\%) & Negative responses (\%) & Total \\
\hline 1 & Knowledge of extra-label status of ceftriaxone & $26(32.5)$ & $54(67.5)$ & 80 \\
& Application of culture and sensitivity test before use & $3(11.5)$ & $23(88.5)$ & 26 \\
2 & Knowledge of ceftriaxone as one of the drugs of last resort & $57(71.2)$ & $23(28.8)$ & 80 \\
& Application of culture and sensitivity before use & $11(19.3)$ & $46(80.7)$ & 57 \\
\hline
\end{tabular}


Int J Vet Sci, 2021, 10(3): 220-228.

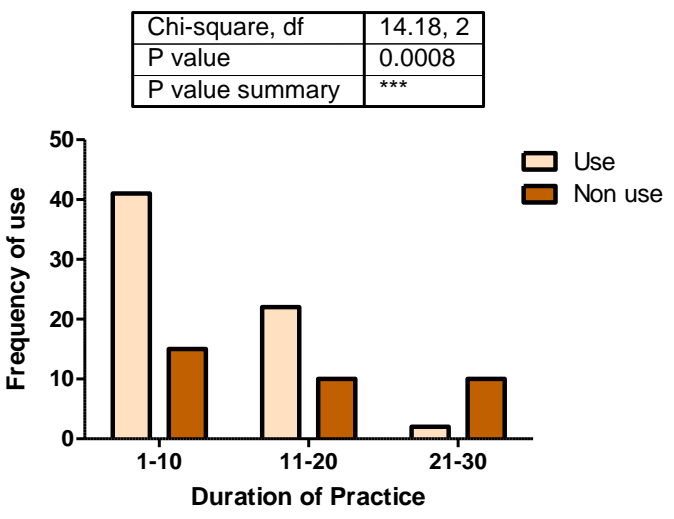

Fig. 1: Duration of veterinary practice and inclination to use ceftriaxone for treatment of bacterial infection.

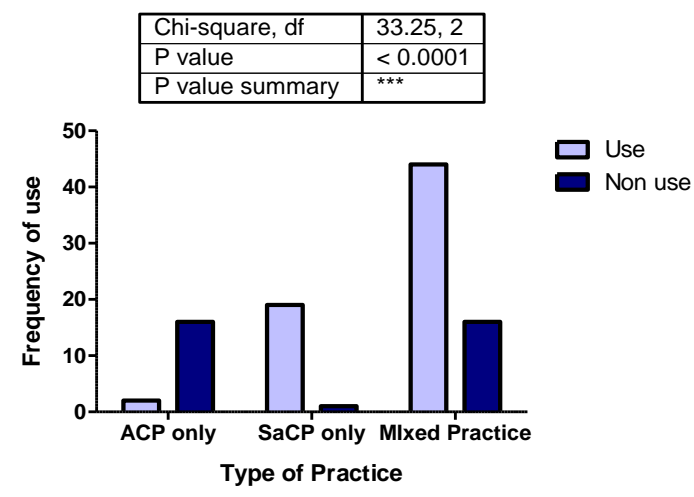

Fig. 2: Veterinary practice type and use of ceftriaxone: $\mathrm{ACP}=$ avian clinical practice: $\mathrm{SaCP}=$ small animal clinical practice.

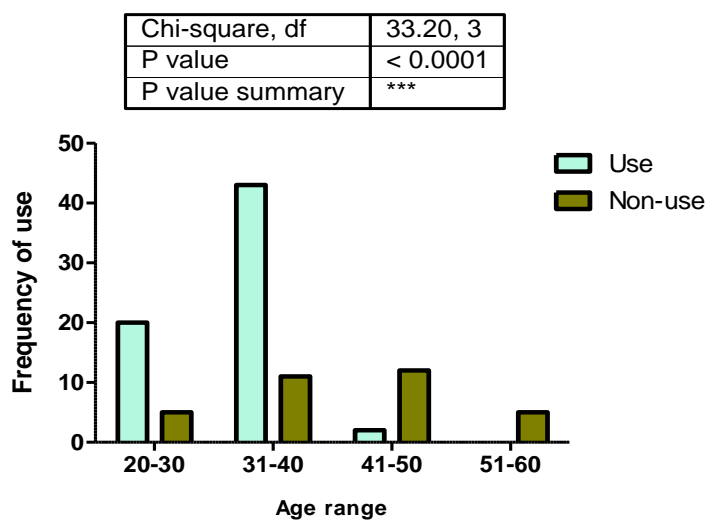

Fig. 3: Age of respondents and inclination to use ceftriaxone in the treatment of dog.

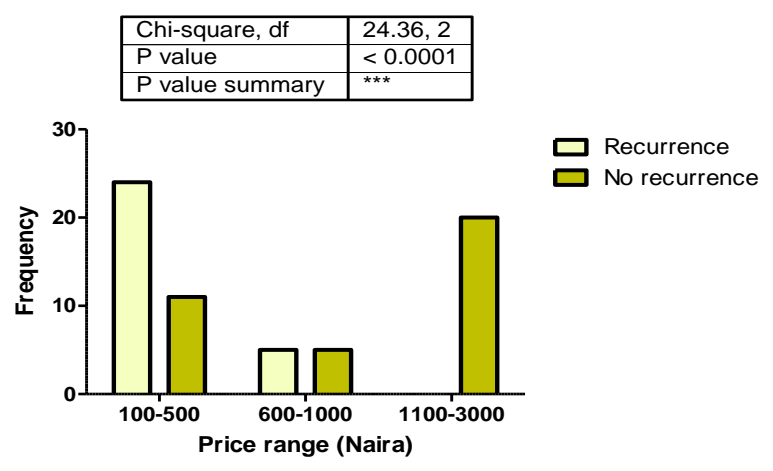

Fig. 4: Brand price of ceftriaxone used by respondents and the frequency of infection recurrence associated with the use of the brands.

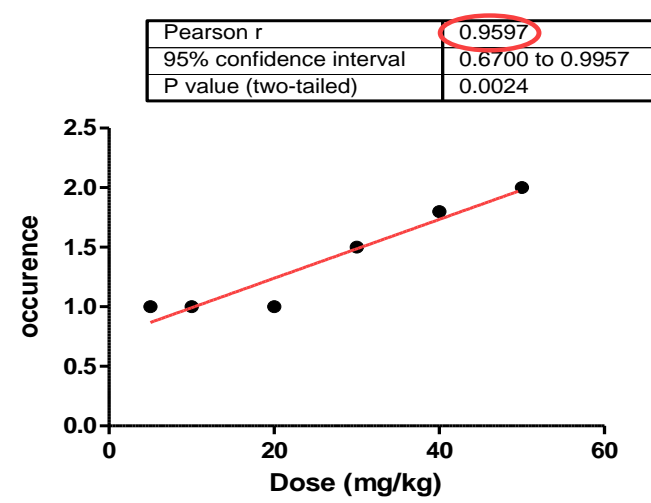

Fig. 5: Correlation between dose of ceftriaxone administered and side effect manifestation in dogs.

\begin{tabular}{|l|l|}
\hline Pearson $r$ & 0.9857 \\
\hline 95\% confidence interval & 0.7936 to 0.9991 \\
\hline P value (two-tailed) & 0.0020 \\
\hline P value summary & $\star \star$ \\
\hline
\end{tabular}

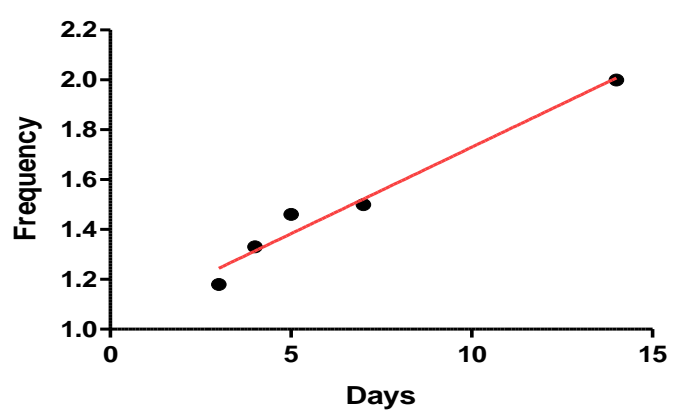

Fig. 6: Correlation between the duration of treatment with ceftriaxone and development of side effect.

\begin{tabular}{|l|l|}
\hline Pearson $r$ & -0.7041 \\
\hline 95\% confidence interval & -0.9785 to 0.4706 \\
\hline$P$ value (two-tailed) & 0.1844 \\
\hline$P$ value summary & $\mathrm{ns}$ \\
\hline
\end{tabular}

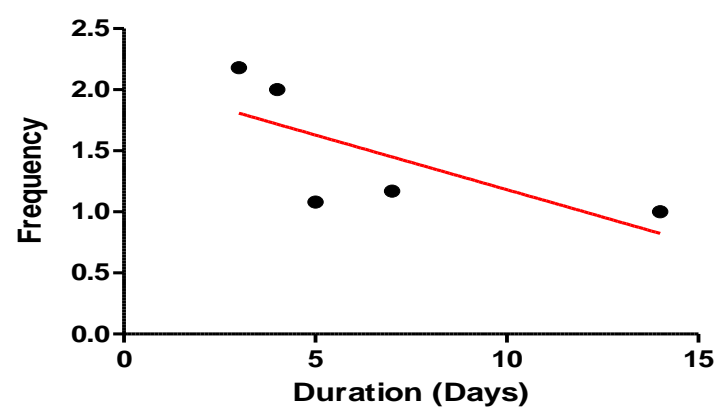

Fig. 7: Correlation between the duration of treatment with ceftriaxone and manifestation of recurrence of infection after treatment in dogs.

\section{DISCUSSION}

This study was undertaken to assess knowledge, attitude, and practices of veterinarians towards the use of ceftriaxone in dogs in Enugu State, Nigeria. The response (98\%) to the questionnaire was quite commendable and could be attributed to the fact that the respondents were all professionals that appreciate the import of research and understood the questions posed to them. This response was similar to what was obtained in previous studies also 
involving professionals, on the use of antibiotics in humans and animals (WOAH 2008; Singh 2010; Faizullah et al. 2017; Amer et al. 2020). From the respondent biodata, it was observed that most practicing veterinarians in the study area were male $(69 \%)$. It was also observed that most of the respondents were between the ages 31-40 years $(58.3 \%)$ and were more inclined to use ceftriaxone than the older respondents. This was corroborated by the inclination of the respondents who have practiced for 1-10 years to the use of ceftriaxone in treatment of bacterial infection. This could be because the younger generations of veterinarians have no patience to rationally prescribe antibiotic based on laboratory test results unlike the older vets and probably because ceftriaxone became more available few decades ago. It is worthy to note that a good number of the respondents have advanced in their career by obtaining an M.Sc $(41.7 \%)$. Most $(85 \%)$ of the Veterinarians who responded to the questionnaire have practiced for more than 1 year and had acquired long enough experience to provide reliable responses to most of the questions in the questionnaire.

In this study, we observed that $63 \%$ of the respondents treat pets with ceftriaxone; and $90 \%$ of the 50 respondents do that without conducting bacterial culture and sensitivity test. This observation is similar to other reports from developing countries where there are indiscriminate use of antimicrobials in humans and animals which may eventually lead to antimicrobial resistance (Singh 2010; Faizullah 2017; Parkunan et al. 2019; Glasgow et al. 2019), a most feared consequence. Ceftriaxone is a highly valued antibiotic in human medicine as it is one of the drugs of last resort in clinically ill patients (Joynt et al. 2001; Oduyebo et al. 2017); therefore, its use should be regulated. However, from this study, the respondents reported using this drug in treating food animals. Just like the commonly used antibiotics (tetracycline, Gentamicin, penicillin and streptomycin combination, etc, ceftriaxone is currently being indiscriminately used by veterinarians in the study area. The danger in this trend is that even if new drugs are being produced, they will eventually be abused and then emergence of resistant microbes to the drug will be inevitable, especially due to its use in food animals which may lead to its residues being present in foods of animal origin. In this study, it was also observed that some veterinarians use ceftriaxone in the treatment of mild infection without conducting sensitivity test, even worse is its use as a prophylaxis. The prophylactic use of antibiotics has been reported among livestock farmers to prevent morbidity and mortality (Prescott and Boerlin 2008; Kumar et al. 2019), a behavior heavily linked to the emergence of resistant bacteria. The lack of antibiotic stewardship by the respondents and the fact that they are aware of antimicrobial resistance and its implication is a wakeup call for drug regulatory body, the government and the general populace as this is a public health threat.

The result of this study showed that there was a significant association between brand prices of ceftriaxone and recurrence of infection after treatment indicating, the cheaper the brand of ceftriaxone, the more likely the infection will recur after treatment. This report differed from a study conducted in Afghanistan, where no significant correlation was observed among price, brand, and efficacy of ceftriaxone sodium against S. aureus (Naimi et al. 2016). The difference could probably be that some brands did not contain up to the therapeutic dose of ceftriaxone (1\% ceftriaxone sodium). Most (73.8\%) of the respondents use the cheapest brands (0.27-1.37 USD) of ceftriaxone and only a few $(26.2 \%)$ use highly priced brands (6.86-8.23 USD) of ceftriaxone in treatment of canine bacterial diseases. This is probably due to the financial capacity of the client and the value placed on the sick dogs. It can be speculated that those few respondents who used "expensive" ceftriaxone brand could have used it on highly priced exotic breed/cherished dogs where the owners could possibly afford the high fees. A good number of the respondents used ceftriaxone at the dose of $5-10 \mathrm{mg} / \mathrm{kg}$, this may be an under-dose for the dogs. Administration of under-dose of antibiotics is very dangerous as it is one of the ways in which resistant bacteria are formed. Veterinarians that give $5-10 \mathrm{mg} / \mathrm{kg}$ of ceftriaxone to their patients were among the $43.3 \%$ who reported recurrence of infection after treatment with ceftriaxone. Some of the respondents used maximum dose of $40-50 \mathrm{mg} / \mathrm{kg}$. This dose of drug in dogs has its major draw-backs especially when used for a prolonged period of time. Those respondents who reported encountering some adverse reaction with the use of ceftriaxone were those that treat the animals for 7 days and beyond with the maximum dose of $40-50 \mathrm{mg} / \mathrm{kg}$. Most of the veterinarians treat their patients once daily with ceftriaxone. This regiment seems good enough as it is recommended by workers who did a pharmacokinetic study on ceftriaxone in other animal species (Gardner and Aucoin 1994; Joyntet al. 2001; Dardi et al. 2004). However, Eke et al. (2020), recommended a four hourly treatment of ceftriaxone at $25-50 \mathrm{mg} / \mathrm{kg}$ in dogs as it undergoes rapid elimination with a short elimination half-life in this species. It was most surprising to find out that most veterinarians were unaware of both the extra-label and last resort status of ceftriaxone, despite the advancement in their career (41.7\% having M.Sc). However, the few that knew that ceftriaxone is one of the drugs of last resort still used it to treat mild cases and prevent secondary bacterial infection without conducting sensitivity test. This drug should not be a first line treatment; rather it should be used in the treatment of severe bacterial diseases. This behavior is unprofessional and should be frowned at by relevant authority. The abuse of ceftriaxone by Veterinarians has shown that the drug enforcement agency in Nigeria is not very efficient and the laws guiding the usage of antibiotics if in existence are not enforced However, this condition is not only peculiar to Nigeria, Faizullah et al. (2017) reported that none of the medical doctors in Khyber Pakhtun Khawah, Pakistan performed or advised for culture and sensitivity test before using antibiotics; García et al. (2011) also reported that $90 \%$ of the antibiotics prescribed in Bangladesh were done without laboratory findings. Singh (2010) also reported indiscriminate use of antibiotics in equines in India. A report from Trinidad showed that doctors hardly request for laboratory analysis as they felt that culture and sensitivity tests are unimportant and time-consuming (Mohan et al. 2004). A study done on the use of antimicrobials by small animal veterinarians in South Africa showed that $91.2 \%$ of the veterinarians use 
antimicrobials empirically before laboratory tests are being carried out, while $86.2 \%$ use off label human drugs in animals (Chipangura 2017). In this study, almost $70 \%$ of the respondents indicated that they do not run sensitivity tests before commencing treatment with ceftriaxone because of unavailability of standard microbiology laboratories especially for those in private practice. This will be corrected by the regulatory bodies ensuring that microbiology laboratories are up to standard before starting operation and also monitoring them to make sure that the standard is maintained. Rational prescription when done through following strictly the result of culture and sensitivity test (adoption of antibiotic stewardship program) is the most important way to reduce antibiotic resistance (CDC 2013; FDA 2017; AVMA 2018).

The adverse drug reactions including pale mucous membrane, mucopurulent eye discharge, paralysis of the hind limb and death reported by the respondents were similar to what was reported in humans treated with ceftriaxone for a prolonged time (Denish et al. 2008). The diarrhea reported in this study may be due to prolonged use of the antibiotic and the consequent distortion of the microflora. This is similar to what was observed in mares where gastrointestinal disturbances including severe colitis was noted with ceftriaxone administration (Gardner and Aucoin 1994).

Extravagant use of ceftriaxone is a great public health concern and drug enforcement agency should ensure that ceftriaxone be used in pets as drug of last resort only in very severe bacterial infection after drug sensitivity has been conducted. This could be done using educational activities to increase awareness on antimicrobial stewardship program and judicious ceftriaxone and other antimicrobial use practices among veterinarians. Kumar et al. (2019) proposed the adoption of increase index of antibiotic resistance awareness to curb the emergence of AMR. This index involves; general awareness of the case presented, approaches to best diagnosis, clinical practices, awareness of the consequences, prescription-related awareness, surveillance-related awareness, awareness of possible transfer of resistant bacteria from animal to man and vice versa and awareness of ethics. These awareness index values if enhanced will help veterinarians and human doctors to make accurate diagnosis and rational prescription of antibiotics. Veterinarians could also update their knowledge on antimicrobial use through continuous education, use of internet and advancement of their carrier through membership and fellowship diploma programs.

Other important and effective ways to reduce emergence of AMR is by prohibiting random use of antibiotics, educating the public and stakeholders especially livestock farmers and pet owners on the implication of indiscriminate use of antibiotics and benefits of judicious antibiotic use. This could be done by holding public seminars and public education through television or radio jingles. Eliminating the use of subtherapeutic doses of antibiotics in animal production, encouraging bio-security and phage therapy as alternatives to antibiotic medication and most importantly, gaining political and financial support from policy makers.

\section{Conclusion}

This study has shown that veterinarians in Enugu State, Nigeria do not just prescribe ceftriaxone to dogs and livestock, but they do so without conducting sensitivity tests.

\section{Limitations of the Study}

There is a possibility of recall bias by the respondents in remembering some questions. The diseases or the clinical symptoms which prompted the vets to resort to ceftriaxone in relation to the dose, duration and treatment regimen which would have been helpful to understand the practice of judicious use of Ceftriaxone were unfortunately not included in the questionnaire.

\section{Author's Contribution}

UUE and IGE Conceptualized the idea of study. UUE, IGE, AOA, EVE, IJU and BMA carried out the study and collected the data. UUE, IGE and AOA provided the resources. BMA supervised all the work. , Validation, EVE, UUE; Visualization, UUE and EVE wrote the manuscript. All authors have read and agreed to the published version of the manuscript.

\section{REFERENCES}

Amer MM, Amer AM, Hassan ER and Ghetas AM, 2020. Salmonella Enteritidis in broiler chickens: isolation, antibiotic resistance phenotyping and efficacy of colistin on control of experimental infection. International Journal of Veterinary Science 9: 267-272.

Aslam B, Wang W, Arshad MI, Khurshid M, Muzammil S, Rasool MH, Nisar MA, Alvi RF, Aslam MA, Qamar MU, Salamat MKF and Baloch Z, 2018. Antibiotic resistance: a rundown of a global crisis. Infection and Drug Resistance 11: 1645-1658. https://doi.org/10.2147/IDR.S173867

AVMA, 2018. American Veterinary Medical Association. VCPR: The veterinarian-client-patient relationship. https://www.avma.org/KB/Resources/Reference/Pages/VC PR.aspx, Accessed 18 July 2018

Bengtsson B and Greko C, 2014. Antibiotic resistanceconsequences for animal health, welfare, and food production. Upsala Journal of Medical Sciences 119: 96102. https://doi.org/10.3109/03009734.2014.901445

Boeckel TPV, Gandra S, Ashok A, Caudron Q, Grenfell BT, Levin SA and Laxminarayan R, 2014. Global antibiotic consumption 2000 to 2010: an analysis of national pharmaceutical sales data. The Lancet Infectious Diseases 14: 742-750. https://doi.org/10.1016/S1473-3099(14) 70780-7

Boerlin P and Reid-Smith RJ, 2008. Antimicrobial resistance: Its emergence and transmission. Animal Health Research Reviews 9: 115-126. https://doi.org/10.1017/S146625230 $\underline{800159 \mathrm{X}}$

CDC, 2013. Center for Disease Control and Prevention, 2013. Antibiotic resistance threats in the United States. [Accessed March 19, 2014]. Available at: http://www.cdc.gov/drugresistance/threat-report-2013/pdf/ ar-threats-2013-508.pd

Chipangura K, Eagar H, Kgoete M, Abernethy D and Naido V, 2017. An investigation of antimicrobial usage patterns by small animal veterinarians in South Africa. Preventive Veterinary Medicine 136: 29-38. https://doi.org/10.1016/ j.prevetmed.2016.11.017

Chung YS, Hu YS, Shin S, Lim SK, Yang SJ, Park YH and Park KT, 2017. Mechanisms of Quinolone resistance in Escherichia coli isolated from companion animals, pet- 
owners, and non-pet-owners. Journal of Veterinary Science 18: 449-456. https://doi.org/10.4142/jvs.2017.18.4.449

Colakoglu EC, Haydardedeoglu AE, Alihosseini H and Hayirli A, 2017. Efficacy of single-dose ceftriaxone versus multiple-dose enrofloxacin in dogs with uncomplicated lower urinary tract infection: a randomized clinical trial. Veterinary Medicine (Praha) 62: 125-130. https://doi.org/ 10.17221/23/2016-VETMED

Dardi M S, Sharma SK and Srivastava AK, 2004. Pharmacokinetics and dosage regimen of ceftriaxone in buffalo calves. Veterinary Research Communications 28: 331-338.

Denish D, Dugan N and Carter J, 2008. Intravascular haemolysis in patient on ceftriaxone with demonstration of anticeftriaxone antibody. Internal Medicine Journal 38: 438-441.

Eke IG, Eze UU, Anaga AO, Chah KF, Anene BM and Asuzu IU, 2020. Disposition kinetics of ceftriaxone and determination of its therapeutic dose in dogs. Tropical Journal Pharmaceutical Research 19: 1753-1758. http://dx.doi.org/10.4314/tjpr.v19i8.26

European Commission, 2017. A European one health action plan against antimicrobial resistance (AMR). Available online: https://eur-lex.europa.eu/legal-content/EN/TXT/PDF/?uri= CELEX:52017DC0339\&from=EN (accessed on 25 April 2019).

Faizullah M, Rahman N, Umar MI, Anwar M and Sarfraz M, 2017. A cross-sectional study on knowledge, attitude and practices of medical doctors towards antibiotic prescribing patterns and resistance in Khyber PakhtunKhawah, Pakistan. Journal of Applied Pharmaceutical Science 7: 038-046. https://doi.org/10.7324/JAPS.2017.71205

García C, Llamocca LP, García K, Jiménez A, Samalvides F and Gotuzzo E, 2011. Knowledge, attitudes and practice survey about antimicrobial resistance and prescribing among physicians in a hospital setting in Lima, Peru. BMC Clinical Pharmacology 11: 18. https://doi.org/10.1186/ 1472-6904-11-18

Gardner SY and Aucoin DP, 1994. Pharmacokinetics of ceftriaxone in mare. Journal of Veterinary Pharmacology and Therapeutics 17: 155-157. https://doi.org/10.1111/ j.1365-2885.1994.tb00226.x

Gashe F, Mulisa E, Mekonnen M and Zeleke G, 2018. Antimicrobial resistance profile of different clinical isolates against third-generation cephalosporins. Journal of Pharmaceutics (Cairo) 2018: 5070742. https://doi.org/ $\underline{10.1155 / 2018 / 5070742}$

GavaldàJ,López P,Martín T, Gomis X, Ramírez JL, Azuaje C, Almirante B andPahissa A, 2002. Efficacy of ceftriaxone and gentamicin given once a day by using human-like pharmacokinetics in treatment of experimental staphylococcal endocarditis. Antimicrobial Agents and Chemotherapy 46: 378-384. https://doi.org/10.1128/aac. 46.2.378-384.2002

Glasgow L, Forde M, Brow D, Catherine M, Fletcher S and Rodrigo S, 2019. Antibiotic use in poultry production in Grenada. Veterinary Medicine International 2019: 6785195. https://doi.org/10.1155/2019/6785195

Guardabass L, Loeber ME and Jacobson A, 2004. Transmission of multiple antimicrobial-resistant Staphylococcus intermedius between dogs affected by deep pyoderma and their owners. Veterinary Microbiology 98: 23-27. https://doi.org/10.1016/j.vetmic.2003.09.021

Joynt GM, Lipman J, Gomersall CD, Young R.J, Wong ELY and Gin T, 2001. The pharmacokinetics of once-daily dosing of ceftriaxone in critically ill patients. Journal of Antimicrobial Chemotherapy 47: 421-429. https://doi.org/ $\underline{10.1093 / \mathrm{jac} / 47.4 .421}$
Kapil A, 2005. The challenge of antibiotic resistance; need to contemplate. Indian Journal of Medical Research 121: 8391.

Kumar V, Gupta J and Meena HR, 2019. Assessment of Awareness about Antibiotic Resistance and Practices Followed by Veterinarians for Judicious Prescription of Antibiotics: An Exploratory Study in Eastern Haryana Region of India. Tropical Animal Health and Production 51: 677-687. https://doi.org/10.1007/s11250$\underline{018-1742-0}$

Loeffler A, Boag AK, Sung J, Lindsay JA, Guardabassi L, Dalsgaard A, Smith H, Stevens KB and Lloyd DH, 2005. Prevalence of methicillin-resistant Staphylococcus aureus among staff and pets in a small animal referral hospital in the UK. Journal of Antimicrobial Chemotherapy 56: 692697. https://doi.org/10.1093/jac/dki312

Marshall BM and Levy SB, 2011. Food animals and antimicrobials: impacts on human health. Clinical Microbiology Reviews 24: 718-733. https://doi.org/ 10.1128/CMR.00002-11

McEachran AD, Blackwell BR, Hanson JD, Wooten KJ, Mayer GD, Cox SB and Smith PN, 2015. Antibiotics, bacteria, and antibiotic resistance genes: Aerial transport from cattle feed yards via particulate matter. Environmental Health Perspective 123: 337. https://doi.org/10.1289/ehp.1408555

Mehmood K, Bilal RM and Zhang H, 2020. Study on the genotypic and phenotypic resistance of tetracycline antibiotic in Escherichia coli strains isolated from free ranging chickens of Anhui Province, China. Agrobiological Records 2: 63-68. https://doi.org/10.47278/ journal.abr/2020.014

Mohan S, Dharamraj K, Dindial R, Mathur D, Parmasad V, Ramdhanie J, Mattew J and Perira LMP, 2004. Physician behavior for antimicrobial prescribing for pediatric upper respiratory tract infections: a survey in general practice in Trinidad, West Indies. Annals of Clinical Microbiology Antimicrobials 3: 11 .

Mohsin M, Van Boeckel TP, Saleemi MK, Umair M, Naseem MN, He C, Khan A, and Laxminarayan R, 2019. Excessive use of medically important antimicrobials in food animals in Pakistan: a five-year surveillance survey, Global Health Action, 12(sup1): 1697541. https://doi.org/10.1080/ 16549716.2019 .1697541

Muhie OA, 2019. Antibiotic use and resistance pattern in Ethiopia: systematic review and meta-analysis. International Journal of Microbiology ID 2489063. https://doi.org/10.1155/2019/2489063

Naimi HM, Rasekh H, Rahimi MH and Yousofi H, 2016. Assessment of the price-efficacy relationship for multiple brands of ceftriaxone sodium in Kabul: a cross-sectional study. BMC Research Notes 9: 86. https://doi.org/ $\underline{10.1186 / \mathrm{s} 13104-016-1904-\mathrm{y}}$

Oduyebo OO, Olayinka AT, Iregbu KC, Versporten A, Goossens H, Nwajiobi-Princewill PI, Jimoh O, Ige TO, Aigbe AI, Ola-Bello OI, Aboderin AO and Ogunsola FT, 2017. A point prevalence survey of antimicrobial prescribing in four Nigerian Tertiary Hospitals. Annals of Tropical Pathology 8: 42-46. https://doi.org/10.4103/ atp.atp_38_17

Oloso NO, FagboS ,Garbati M, Olonitola SO, Awosanya EJ , Aworh MK, Adamu H, Odetokun IA and Fasina FO, 2018. Antimicrobial resistance in food animals and the environment in Nigeria: A review. International Journal of Environmental research and Public Health 15: 1284 https://doi.org/10.3390/ijerph15061284

Parkunan T, Ashutosh M, Bharathy S, Cherta JS, Ramadas S, Chandrasekhar B, Kumar SA, Sharma R, Kumar MS and De S, 2019. Antibiotic resistance: A cross-sectional study on knowledge, attitude, and practices among veterinarians 
of Haryana state in India. Veterinary World 12: 258-265. https://doi.org/10.14202/vetworld.2019.258-265

Pomba C, Rantala M, Greko C, Baptiste KE, Catry B, E. van Duijkeren E, Mateus A, Moreno MA, Pyorala S, Ruzauskas M, Sanders P, Teale C, Threlfall EJ, Kunsagi Z, TorrenEdo J,Jukes H and Torneke K, 2017. Public health risk of antimicrobial resistance transfer from companion animals. Journal of Antimicrobial Chemotherapy 72: 957-968. https://doi.org/10.1093/jac/dkw481

Prescott JF and Boerlin P, 2016. Antimicrobial use in companion animals and Good Stewardship Practice. Veterinary Record 179: 486-488. https://doi.org/10.1136/ vr.i5908

Singh BR, 2010. Antimicrobial drug uses by veterinarians in equine clinical cases in India, Research Journal of Veterinary Science 3: 165-178. https://doi.org/10.3923/ rjvs.2010.165.178

Tapas KS, 2013. Single dose intravenous ceftriaxone therapy in acute mastitis without and with adjunct therapy of single oral dose of a polyherbal drug. Journal of Veterinary Science and Technology 4: 4. http://dx.doi.org/10.4172/ 2157-7579.S1.004

U.S. Food and Drug Administration (FDA), 2017. Judicious use of antimicrobials for beef cattle veterinarians https://www.fda.gov/downloads/AnimalVeterinary/SafetyH ealth/AntimicrobialResistance/JudiciousUseofAntimicrobia 1s/UCM095568.pdf. Accessed 22 July 2018
U.S. Food and Drug Administration (FDA), 2018. Extra label use and antimicrobials, 10903 New Hampshire Avenue Silver Spring, MD 209931-888-INFO-FDA (1-888-4636332), Page Last Updated: 08/24/2018.

Van Boeckel TP, Brower C, Gilbert M, Grenfell BT, Levin SA, Robinson TP, Teillant A, and Laxminarayan R, 2015. Global trends in antimicrobial use in food animal. Proceedings of the National Academy of Sciences of the United States of America 112: 5649-5654. https://doi.org/10.1073/pnas.1503141112

Ventola CL, 2015. The antibiotic resistance crisis-part 1: causes and threats. Pharmacy and Therapeutics 40: 277-283.

World Health Organization (WHO), 2015. Global Action Plan on Antimicrobial Resistance. Available online: https://apps.who.int/iris/bitstream/handle/10665/193736/97

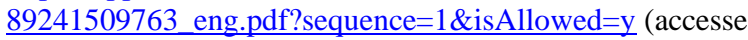
d on 15 May 2017).

World Health Organization (WHO), 2016. Critically important antimicrobials for human medicine ranking of medically important antimicrobials for risk management of antimicrobial resistance due to non-human use. 5th Revision. WHO Advisory Group on Integrated Surveillance of Antimicrobial Resistance (AGISAR). Geneva, Switzerland. ISBN 978-92-4-151222-0

World Organization for Animal Health (WOAH), 2008. Whether diclofenac is already widely stocked and sold in Tanzania. Partners in other African countries. OIE Bulletin 2008-2. 